\title{
Authors' reply: Benefit and risks of trivalent 2010 seasonal influenza vaccine in Australian children
}

H Kelly (heath.kelly@mh.org.au)1', D Carcione², G Dowse², P Effler ${ }^{2}$

1. Victorian Infectious Diseases Reference Laboratory, Melbourne, Australia

2. Communicable Disease Control Directorate, Department of Health Western Australia, Perth, Australia

Citation style for this article:

Kelly H, Carcione D, Dowse G, Effler P. Authors' reply: Benefit and risks of trivalent 2010 seasonal influenza vaccine in Australian children.

Euro Surveill. 2010;15(40):pii=19681. Available online: http://www.eurosurveillance.org/ViewArticle.aspx?Articleld=19681

Article published on 7 October 2010

To the editor: Dr Lopert from Australia's regulatory body for therapeutic goods, the Therapeutics Goods Administration (TGA), raises a number of issues about our quantification of the risk-benefit ratio for seasonal trivalent influenza vaccines administered to children aged six months to four years in Australia in 2010 [1]. While we continue to believe the current data support vaccination of healthy children, it is important to conduct robust post-marketing surveillance, support an open scientific discussion of the observations, and ensure a rapid, comprehensive response to any potential adverse events following immunisation (AEFI).

The authors of the Cochrane review of influenza vaccine effectiveness in children have commented on the relative paucity in the public domain of good quality safety data on influenza vaccines for children aged less than five years [2]. Risk-benefit estimations, such as the approach we have explored, are also uncommon. However, one should not dismiss febrile convulsions as an adverse event. Febrile convulsions would be expected only rarely as demonstrated in a recent large population-based safety study which reported no significantly elevated risk for adverse events (including seizures in children) following administration of more than one million doses of trivalent influenza vaccine to children under the age of 18 years between 2005 and 2008 in the United States [3].

Our rapid communication to Eurosurveillance aimed to explore a method to quantify both risk and benefit [4] and was prompted by the TGA status report of 1 July 2010 that describes the investigation of an observed increase in febrile convulsions in young children following receipt of seasonal influenza vaccine in Australia [5] and contains a detailed analysis of risk by the vaccine manufacturer CSL Biotherapies. We did this after governments in New Zealand and Australia had recommended against using the CSL vaccines in children aged less than five years [4] and after the CSL vaccines had been licensed for use in the United States only for children nine years or older [6]. Our results support this decision. Moreover we indicated that our estimate of an unfavourable risk-benefit ratio applied only to one vaccine manufacturer in one year. Generalisation to wider vaccine programmes would have been inappropriate.

Three of the four authors of our article are involved in the Western Australian programme aimed at assessing the public health impact of providing seasonal influenza vaccines to children aged less than five years. We believe that our involvement in promoting a vaccination programme to protect children from influenza, while being prepared to examine both the risks and the benefits of this programme, does not constitute a conflict of interest.

We chose to examine hospital admission for a febrile convulsion within 24 hours of receipt of seasonal influenza vaccine because hospital admission (or prolongation of hospital admission) is one of the four serious AEFI identified by the World Health Organization. The other three are death, permanent disability and any event that is life-threatening [7]. We acknowledge that hospital admission for febrile convulsion may be of shorter duration than hospital admission for influenza and that associated morbidity may be different, but suggest it is important not to underestimate the impact of either cause of hospital admission. It is also important to compare outcomes in the current context

Since 2008 , for reasons we outlined in our rapid communication, Western Australia has conducted a population-wide vaccination programme aimed at assessing the public health benefits of providing greater access to influenza vaccines for children under five years of age $[8,9]$. This is not a clinical trial, but a programme using influenza vaccines licensed for use pre-school aged children, evaluated by observational studies. It is consistent with recommendations in the Australian Immunisation Handbook which states: 'Annual influenza vaccination is recommended for any person $>6$ months of age who wishes to reduce the likelihood of becoming ill with influenza' [10]. Universal vaccination of healthy children in this age cohort has been recommended by the Advisory Committee on Immunization Practices in the United States since 2006 [11]. 
Moreover a study from South Australia supports the need to evaluate a policy of providing influenza vaccine to healthy children, as well as those with known underlying conditions. The study demonstrated that $81 \%$ of children aged less than five years admitted to hospital with influenza between 1996 and 2006 had no documented risk factor that increased their risk of a serious outcome following infection [12].

We believe assessing risk and benefit will ultimately improve confidence in vaccine programmes.

\section{References}

1. Lopert R. Benefit and risks of trivalent 2010 seasonal influenza vaccine in Australian children. Euro Surveill. 2010;15(40): pii=19679. Available from: http://www. eurosurveillance.org/ViewArticle.aspx?Articleld=19679

2. Smith S, Demicheli V, Di Pietrantonj C, Harnden AR, Jefferson T, Matheson NJ, et al. Vaccines for preventing influenza in healthy children. Cochrane Database Syst. Rev. 2006;(1):CDo04879.

3. Greene SK, Kulldorff M, Lewis EM, Li R, Yin R, Weintraub ES, et al. Near real-time surveillance for influenza vaccine safety: proof-of-concept in the Vaccine Safety Datalink Project. Am J Epidemiol. 2010;171(2):177-88.

4. Kelly H, Carcione D, Dowse G, Effler P. Quantifying benefits and risks of vaccinating Australian children aged six months to four years with trivalent inactivated seasonal influenza vaccine in 2010. Euro Surveill. 2010;15(37):pii=19661. Available from: http://www.eurosurveillance.org/ViewArticle. aspx?Articleld $=19661$

5. Australian Government. Therapeutics Goods Administration. Investigation into febrile reactions in young children following 2010 seasonal trivalent influenza vaccination. Status report as at 2 July 2010. Available from: http://www.tga.gov.au/alerts/ medicines/fluvaccine-report100702.htm

6. Centers for Disease Control and Prevention (CDC)

Advisory Committee on Immunization Practices (ACIP) issues recommendation for use of CSL influenza vaccine. Infection Control Today. Available from: http://www. infectioncontroltoday.com/news/2010/08/acip-issuesrecommendation-for-use-of-csl-influenza-vaccine.aspx

7. World Health Organization. Surveillance of adverse events following immunisation against yellow fever. Geneva; 2010. Available from: http://whqlibdoc.who.int/hq/2010/WHO_HSE_ GAR_ERI_2010.1_eng.pdf

8. Kelly H, Jacoby P, Dixon G, Moore HC, Carcione D, Williams $\mathrm{S}$, et al. Vaccine effectiveness against laboratory-confirmed influenza in healthy young children: a case control study. Pediatr Infect Dis J. Accepted for publication 22 July 2010.

9. Dixon GA, Moore HC, Kelly H, Jacoby P, Carcione D, Williams $\mathrm{S}$, et al. Lessons from the first year of the WAIVE study investigating the protective effect of influenza vaccine against laboratory-confirmed influenza in hospitalised children aged 6-59 months. Influenza Other Respi Viruses. 2010; 4(4):231-4.

10. Australian Government. Department of Health and Ageing. National Health and Medical Research Council. The Australian Immunisation Handbook. 9th edition 2008. Available from: http://www.health.gov.au/internet/immunise/publishing.nsf/ Content/Handbook-home

11. Centers for Disease Control and Prevention (CDC) Advisory Committee on Immunization Practices (ACIP). Prevention and control of influenza with vaccines. Recommendations of the Advisory Committee on Immunisation Practices. Available from: http://www.cdc.gov/mmwr/preview/mmwrhtml/rr5510a1. htm.

12. D'Onise K, Raupach JC. The burden of influenza in healthy children in South Australia. Med J Aust. 2008;188(9):510-3. 